\title{
Impact Energy Absorption of Three Mouthguard Materials for Three Environments
}

\author{
A Thesis \\ Presented in Partial Fulfillment of the Requirement for \\ The Degree Master of Science in the \\ Graduate School of The Ohio State University \\ By \\ Darin Randall Lunt, D.D.S. \\ $* * * * *$ \\ The Ohio State University \\ 2009
}

Master's Examination Committee:

Dr. William A. Brantley, Advisor

Dr. Deborah A. Mendel

Dr. Sarandeep Huja

Dr. F. Michael Beck

Approved by:

Advisor

Graduate Program in Dentistry 


\begin{abstract}
In previous studies at The Ohio State University, significant impact energy absorption differences were found for mouthguard materials tested in dry and wet conditions. Objective: Measure energy absorption of 3 popular mouthguard materials exposed to an artificial saliva (Roxane Laboratories, Columbus, $\mathrm{OH}$ ) and compare to energy absorption for the dry condition and after conditioning in deionized water.
\end{abstract}

Methods: Thirty specimens with $12.7 \mathrm{~cm} \times 12.7 \mathrm{~cm} \times 4 \mathrm{~mm}$ dimensions of (a) ethylene vinyl acetate (EVA; T\&S Dental and Plastics, Myerstown, PA), (b) Pro-form ${ }^{\mathrm{TM}}$ (Dental Resources Inc., Delano, MN), another ethylene vinyl acetate material, and (c) PolyShok ${ }^{\mathrm{TM}}$ (Sportsguard Laboratories, Kent, OH), an ethylene vinyl acetate containing polyurethane, were prepared following manufacturer recommendations. Ten specimens of each material were conditioned for $1 \mathrm{~h}$ at body temperature $\left(37^{\circ} \mathrm{C}\right)$ in the dry condition, deionized water and artificial saliva. Specimens were impacted at $20 \mathrm{mph}$ by a 0.5-inch diameter indenter containing a force transducer (Dynatup Model 9250 HV, Instron Corp., Canton, MA), based upon ASTM (American Society for Testing and Materials) Standard D3763. Energy absorption was determined from the area under the force-time curve during the impact event (approximately 5 or 7 millisec depending on the material). Groups were compared using ANOVA and the Tukey test. Regions near the impact site were examined with an SEM. Results: Energy absorption values, normalized to specimen thickness (mean $\pm \mathrm{SD}$ in $\mathrm{J} / \mathrm{mm}$ ), were: (a) Dry: EVA $(n=10) 4.73 \pm 0.27$, 
Pro-form ${ }^{\mathrm{TM}}(n=10) 3.55 \pm 0.25$, PolyShok ${ }^{\mathrm{TM}}(n=10) 6.32 \pm 0.24$; (b) DI water: EVA ( $n$ $=10) 4.82 \pm 0.40$, Pro-form ${ }^{\mathrm{TM}}(n=10) 3.78 \pm 0.33$, PolyShok ${ }^{\mathrm{TM}}(n=10) 5.87 \pm 0.38$;

(c) Artificial saliva: EVA $(n=10) 5.63 \pm 0.49$, Pro-form ${ }^{\mathrm{TM}}(n=10) 4.01 \pm 0.54$, PolyShok $^{\mathrm{TM}}(n=10) 6.37 \pm 0.55$. PolyShok ${ }^{\mathrm{TM}}$ was the most energy-absorbent material in all three environments. EVA was also significantly more impact resistant than ProForm ${ }^{\mathrm{TM}}$ in all three environments. EVA and ProForm ${ }^{\mathrm{TM}}$ performed significantly better after saliva conditioning than dry or water conditioned, but Polyshok ${ }^{\mathrm{TM}}$ did not show any difference in energy absorption when conditioned in any of the three environments.

Characteristic deformation patterns from impact loading were observed for each material. Conclusions: The superior energy absorption for PolyShok ${ }^{\mathrm{TM}}$ is attributed to the polyurethane additive. 
Dedicated to my family 


\section{ACKNOWLEDGEMENTS}

I would like to thank my thesis committee, Dr. William Brantley, Dr. Deborah Mendel, Dr. Sarandeep Huja, and Dr. Michael Beck for all of their efforts on my behalf to intellectually and enthusiastically support me on this project. I am especially grateful for all the time and effort put in by Drs. Brantley and Mendel to guide and direct me. Dr. Brantley was always there for words of encouragement; his cheery attitude and contagious smile helped me remember to have fun while I worked. Dr. Mendel, and her work with the OSU athletic department, is to thank for the mind-power behind the idea for this project. Together they set the groundwork for bringing this project to fruition.

I thank Tom Grentzer and Scott Schriever from Ashland Chemical for their time and help with the impact testing of the samples.

I thank the Delta Dental Master's Thesis Award Program and the Dr. Hall family athletic fund for providing financial support that enabled me to complete this research project.

I would also like to thank all of the orthodontic residents at Ohio State, especially those in my class: Dana Casaus, Brittany Potts, Jeff Shirck, Belinda Weltman, and Jared Zwick. It has been a pleasure working beside and sharing this residency experience with them. I will always have very fond memories and appreciate all of the friendship and support they have given me. 
Lastly I would like to thank my family. My parents are great examples to me and have been nothing but encouraging and supportive my entire life. My wife Sarah has been my rock. For ten long years she has stood beside me, sacrificed, and cheered me on. I truly wouldn't have been able to do it without her. My three wonderful children: Allie, Kate and Roman make coming home a joy and enabling me to forget all of those difficult days. They are all a constant reminder of why I keep going and strive to be my best. 


\section{VITA}



\section{FIELDS OF STUDY}

Major Field: Dentistry

Specialty: Orthodontics 


\section{TABLE OF CONTENTS}

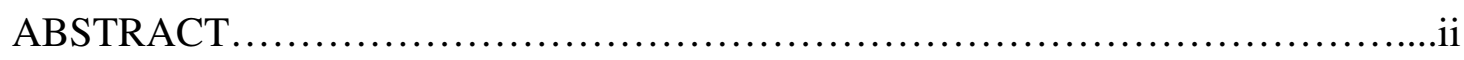

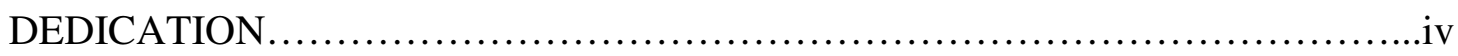

ACKNOWLEDGEMENTS ..............................................



LIST OF TABLES ...................................................

LIST OF FIGURES.....................................................

CHAPTER 1 INTRODUCTION.......................................

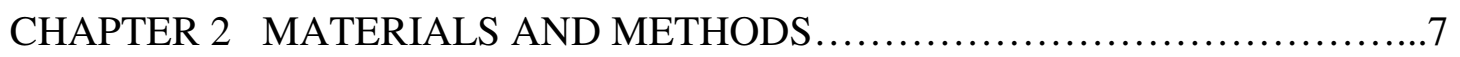

CHAPTER 3 MANUSCRIPT: Impact energy absorption of three mouthguard materials for three environments.............................11

CHAPTER 4 GENERAL CONCLUSIONS................................40

LIST OF REFERENCES ...............................................42 


\section{LIST OF TABLES}

Table

3.1 Results of energy absorption for three materials in three environments.......28

3.2 Summary of statistical comparisons for energy absorption.................29 


\section{LIST OF FIGURES}

Table

3.1 Impact test results for EVA in dry environment......................... 19

3.2 Impact test results for EVA in de-ionized $\mathrm{H} 2 \mathrm{O}$ environment................ 20

3.3 Impact test results for EVA in artificial saliva environment............... 21

3.4 Impact test results for Pro-form ${ }^{\mathrm{TM}}$ in dry environment.................. 22

3.5 Impact test results for Pro-form ${ }^{\mathrm{TM}}$ in de-ionized $\mathrm{H} 2 \mathrm{O}$ environment.......... 23

3.6 Impact test results for Pro-form ${ }^{\mathrm{TM}}$ in artificial saliva environment............24

3.7 Impact test results for PolyShok ${ }^{\mathrm{TM}}$ form in dry environment...............25

3.8 Impact test results for PolyShok ${ }^{\mathrm{TM}}$ in de-ionized $\mathrm{H} 2 \mathrm{O}$ environment........... 26

3.9 Impact test results for PolyShok ${ }^{\mathrm{TM}}$ in artificial saliva environment......... 27

3.10 SEM image near impact site of EVA in dry environment................. 31

3.11 SEM image near impact site of Pro-form ${ }^{\mathrm{TM}}$ in de-ionized water............ 32

3.12 SEM image near impact site of PolyShok ${ }^{\mathrm{TM}}$ in saliva substitute............... 33 


\section{CHAPTER 1}

\section{INTRODUCTION}

The use of mouthguards has long been promoted as a significant way of reducing the incidence of sports and recreational activity related injuries (1). The American Dental Association recognizes the preventive value of oro-facial protection and recommends the use of mouthguards in 29 sports/exercise activities (2). Mouthguards can act as a buffer from trauma and provide a degree of protection for both the mouth's soft tissues (lips, gums, tongue) and hard tissues (teeth and alveolar bone) as well as protection from brain injuries (3). The ability to protect the mouth is highly dependent on the ability of the mouthguard to act as a shock absorber and absorb the force transmitted to the teeth (4).

The protective capability of a particular mouthguard is affected by the geometry of the device as well as the materials used in construction. Not all mouthguards give equal protection and the nature of the material and a "proper fit" correlate to its effectiveness (3). There are basically 3 types of mouthguards that are most commonly used; stock, mouth formed (boil and bite) and custom (laminated or vacuum formed). Stock mouthguards are readily available for purchase and are simply removed from the package and placed in the mouth without any modification. Because they are only a shell 
held in place by clenching, they are the least expensive and least effective. In addition, athletes often further reduce the effectiveness of these poor quality appliances by trimming them to allow for increased comfort and breathing capability. Mouth-formed guards known as boil-and-bite guards are the most commonly used mouthguards on the market and represent $90 \%$ of all mouthguards worn (5). Another inexpensive alternative, they are made of a thermoplastic material that is immersed in boiling water, then fit and formed in the mouth. These do not provide the proper thickness, comfort, or critical protection of the posterior teeth. Custom-made mouthguards are designed by a dentist, taking into account the patient's dental history and the particular sport to be played. These mouthguards are fabricated by using a cast of the patient's dentition and vacuumforming a thermoplastic sheet. Additional layers can be laminated together to provide the thickness needed to provide protection (6).

There are no international standards set for the materials used in the fabrication of mouthguards (7). Numerous different materials are used in their fabrication including: polyvinylacetate-polyethylene or ethylene vinyl acetate (EVA) copolymer, polyvinylchloride, latex rubber, acrylic resin, and polyurethane (3). Each of these polymers can also be manipulated by changing properties such as molecular weight, adding fillers and plasticizers, and copolymerization with other monomers $(8,9)$. The effects of different mechanical and physical properties of each type of material must be examined when considering the effectiveness of a mouthguard. EVA copolymers are the most popular materials, partly because of the ease of custom fabrication and the low cost (10); however, few studies have actually evaluated the physical and mechanical properties of mouthguard materials $(11,12)$. 
Laboratory testing of mouthguard materials has traditionally been done almost exclusively at room temperature $(7,10,12-14)$. DSC studies by Meng et al indicated that there are differences in thermal behavior among the mouthguard materials that may be due to disruption of EVA crystal formation. The endothermic transformation of EVA-based mouthguard materials is near body temperature, so testing of these materials should be performed at body temperature and not at room temperature (15).

Shock-absorbing capability can be broadly defined as the reduction in the impact energy or force transmitted to the surface beneath the mouthguard material. Various methods have been used to try and measure this. Westerman et al built an impact rig and measured the acceleration of the pendulum of the rig, and then used this information to calculate the force transmitted to the material (16). Other mouthguard studies have tried to compare force transmission through different materials by various designs such as indenter and pendulum devices designed to deliver impact forces $(7,13,14,16-21)$. The direct shock-absorption quantification is measured by a transducer beneath the mouthguard when a known force (from an indenter, pendulum, or dropped weight) is applied to the top of the mouthguard material $(4,10-12,22)$. The resulting force is plotted against time to determine the energy absorption behavior.

The impact resistance and energy absorption quality of a mouthguard is generally believed to be proportional to its thickness, especially in the labial and occlusal areas (13, 23). Westerman et al found that a minimal thickness of $4 \mathrm{~mm}$ is required to provide the optimum energy absorption (13). It is difficult, however, to provide a thickness of $4 \mathrm{~mm}$ in the labial and occlusal areas because of a lack of wearer comfort. Player resistance to compliance in wearing mouthguards is found with increased thickness because of 
discomfort, speech interferences, and respiratory restrictions (24). This finding indicates the necessity of improving the impact absorption ability of mouthguards by considering new designs and developing new materials, so that an acceptable level of protection can be produced by a mouthguard with minimal thickness. Patrick et al (25) proposed a multi-layered composite system to address this need. Their sandwich-like design has EVA on both sides and a more compliant material in the center. Westerman et al found a $32 \%$ reduction of force transmission through an air-impregnated material (26). Takeda et al also showed an increase in shock absorption with an EVA material with a hard acrylic insert (27). Despite numerous studies indicating improved energy absorption, most EVA sheets currently marketed for mouthguard fabrication are single-layered.

Very few studies have looked at the microscopic level of mouthguard materials. SEM results reported by Meng et al suggest that processing of materials (EVA, Proform $^{\mathrm{TM}}$, and PolyShok ${ }^{\mathrm{TM}}$ ) has minimal effect on morphology of surface features. They also found that high-speed impact $(20 \mathrm{mph})$ disrupted the microstructure of the materials, whereas low-speed impact (5 mph) appeared to only stretch the materials $(15,28,29)$.

There have been few studies about the effect of the aqueous environment in the oral cavity on mouthguard materials. Many, such as Tran et al (7), have studied the absorptive properties of these materials, but very little research has been performed to understand the impact characteristics of mouthguard materials when subjected to environmental conditions more closely mimicking the oral cavity. Coto et al report that EVA responded positively and showed improved mechanical response as the result of exposure to artificial saliva solution (30). Comparison of recent studies by Mendel et al 
also suggest that mouthguard materials behave differently when conditioned in an aqueous environment versus dry testing $(28,29,31)$.

\section{Statement of Problem}

Sports and recreational activities can result in many types of physical trauma, including damage to the mouth and its supporting structures. Mouthguards have been advocated and used for many years to protect against the dental and facial injuries that may result. By absorbing the energy of forces directed towards the teeth, mouthguards act as a buffer against injury. Not all mouthguards are created equally. The protective capability of a particular mouthguard is determined by a variety of variables including geometry and material. Maeda et al found $4 \mathrm{~mm}$ to be the mouthguard thickness that gave the optimal shock-absorbing protection along with a degree of comfort tolerable enough to maintain wear compliance (23). Mouthguards are made from numerous polymers of different chemical formulations that affect their mechanical and physical properties. The performance of each material must be measured in order to quantify its protection potential. Numerous laboratory tests have utilized impact tests to measure the transmission of impact forces and energy absorption (7, 13, 16-21, 23, 28-30). However, very little testing has been done in a medium that mimics the oral environment.

The objective of this study was to perform impact tests to quantify the energy absorption of three different mouthguard materials (EVA, Pro-form ${ }^{\mathrm{TM}}$, and PolyShok ${ }^{\mathrm{TM}}$ ) that have been conditioned in three different environments; dry, deionized water and artificial saliva. The results of this investigation will help in selection of the optimal 
material to fabricate mouthguards used by The Ohio State University and other sports programs.

\section{Specific Aims}

The specific aims of this research are as follows:

1. To quantify differences in energy absorption, or impact resistance, between mouthguard materials when they are tested at body temperature in three different environments: dry, deionized water-conditioned, and artificial saliva-conditioned.

2. To provide insight into potential fundamental mechanisms at the microstructural level for energy absorption by these mouthguard materials, and to search for differences in impact resistance for specimens in the different environments.

\section{Null Hypotheses}

There are two null hypotheses for this study

1. There is no difference in the energy absorption, or impact resistance, between mouthguard specimens conditioned in dry, deionized water, and artificial saliva environments.

2. There is no difference in the energy absorption, or impact resistance, between the different mouthguard materials-EVA, Pro-form ${ }^{\mathrm{TM}}$, and PolyShok ${ }^{\mathrm{TM}}$. 


\section{CHAPTER 2}

\section{MATERIALS AND METHODS}

\subsection{Mouthguard materials}

Three commercially available mouthguard materials were selected for testing: a conventional ethylene vinyl acetate (EVA, Keystone Industries, Cherry Hill, NJ), serving as the control; Pro-form ${ }^{\mathrm{TM}}$ (Dental Resources Inc, Delano, MN), another ethylene vinyl acetate thermoplastic material; and PolyShok ${ }^{\mathrm{TM}}$ (Sportsguard Laboratories, Kent, OH), an ethylene vinyl acetate product containing polyurethane. All materials were purchased from the manufacturers, verified to be from the same production batch, and tested as received.

\subsection{Material processing}

All materials were processed according to manufacturer recommendations for conventional mouthguard production using a single vacuum forming machine (Raintree Essix model 101, Sarasota, FL). A sheet of mouthguard material obtained from the manufacturer in standard dimensions of $12.7 \mathrm{~cm} \times 12.7 \mathrm{~cm} \times 4 \mathrm{~mm}$ was placed on the vacuum-forming unit. Each specimen was heated at uniform temperature until droop was 
measured to be $3 \mathrm{~cm}$ as verified by a wire measurement jig. The vacuum was then turned on, and the material was lowered and drawn over a master dental stone model of $7.5 \mathrm{~cm} \times$ $7.5 \mathrm{~cm} \times 2.5 \mathrm{~cm}$ dimensions, representing the dental arch. The heating element portion of the unit was turned away, and the vacuum was continued for 1 minute. The stone model and deformed material were removed together from the unit and placed on a flat surface and allowed to cool for 1 hour. The material was then separated from the model, and the center portion of the material was cut out and trimmed into specimens of approximately $7.5 \mathrm{~cm} \times 7.5 \mathrm{~cm}$ in dimensions. The starting thickness of approximately $4 \mathrm{~mm}$ for the asmanufactured materials was decreased during the processing used to prepare the test specimens.

\subsection{Impact testing procedure}

The impact properties of the molded samples were tested on an instrumented impact tester (Dynatup Model 9250 HV, Instron Corp, Canton, MA). The pneumatic clamping fixture of the Instron machine drop-tower apparatus was set with a 3.0-inch diameter opening on the top support ring and a bottom support ring with an opening of approximately 1.5 inches in diameter. Stop blocks set on top of spacers were mounted on the base of the tower to arrest the downward motion of the drop weight. The impacttesting protocol was based upon ASTM Standard D3763 (35). After conditioning, specimens were removed and immediately placed in a test chamber at $37^{\circ} \mathrm{C}$ where they were loaded at $20 \mathrm{mph}$ (miles per hour) by a 0.5 -inch diameter indenter containing a force transducer. Each impact test had a maximum duration of 10 millisec (ms). Energy absorption was determined from the area under the force-time curve during the impact 
event (ranging from 5-7 millisec, depending on the material), using the speed of the impacting indenter (striker) that contained the transducer. Each value of energy absorption was normalized to the measured thickness (NTT) of the specific test specimen. Results were compared using two way ANOVA and the post hoc Tukey test. An initial power analysis from preliminary data had indicated the need for 10 specimens of each material for each condition. Ninety specimens were tested: three materials; EVA, Pro-form ${ }^{\mathrm{TM}}$, and PolyShok ${ }^{\mathrm{TM}}$ in three environments; dry, de-ionized water, and artificial saliva. Ten specimens of each material were tested dry in the environmental chamber at $37^{\circ} \mathrm{C}$. The dry samples were allowed to equilibrate for 1 hour in the $37^{\circ} \mathrm{C}$ chamber prior to being tested. Ten specimens of each material; EVA, Proform ${ }^{\mathrm{TM}}$, and PolyShok ${ }^{\mathrm{TM}}$ were conditioned for 1 hour in $37^{\circ} \mathrm{C}$ deionized water and then transferred to the $37^{\circ} \mathrm{C}$ environmental chamber for immediate testing. Ten specimens of each material; EVA, Pro-form ${ }^{\mathrm{TM}}$, and PolyShok ${ }^{\mathrm{TM}}$ were also conditioned for 1 hour in a $37^{\circ} \mathrm{C}$ saliva substitute solution and then transferred to the $37^{\circ} \mathrm{C}$ environmental chamber for immediate testing.

\subsection{Scanning Electron Microscope Observations}

The mouthguard materials were observed with a scanning electron microscope (SEM) to study the surface morphology qualitatively and learn if there were any surface changes for the different materials and what effect, if any, the different environmental conditions had on them. Sample specimens were cut from the mouthguard materials after the specimens had been subjected to the impact tests. The samples were first cleaned with deionized water to remove surface contaminants and then air-dried. For SEM analysis the 
samples were sputter-coated with a thin gold film. Photomicrographs in digital format were obtained with a Hitachi TM -1000 scanning electron microscope at a range of magnifications. 


\title{
CHAPTER 3
}

\section{MANUSCRIPT: \\ Impact Energy Absorption of Three Mouthguard Materials for Three Environments}

\begin{abstract}
In previous studies at The Ohio State University, significant impact energy absorption differences were found for mouthguard materials tested in dry and wet conditions. Objective: Measure energy absorption of 3 popular mouthguard materials exposed to an artificial saliva (Roxane Laboratories, Columbus, $\mathrm{OH}$ ) and compare to energy absorption for the dry condition and after conditioning in deionized water.

Methods: Thirty specimens with $12.7 \mathrm{~cm} \times 12.7 \mathrm{~cm} \times 4 \mathrm{~mm}$ dimensions of (a) ethylene vinyl acetate (EVA; T\&S Dental and Plastics, Myerstown, PA), (b) Pro-form ${ }^{\mathrm{TM}}$ (Dental Resources Inc., Delano, MN), another ethylene vinyl acetate material, and (c) PolyShok ${ }^{\mathrm{TM}}$ (Sportsguard Laboratories, Kent, OH), an ethylene vinyl acetate containing polyurethane, were prepared following manufacturer recommendations. Ten specimens of each material were conditioned for $1 \mathrm{~h}$ at $37^{\circ} \mathrm{C}$ in the dry condition, deionized water and artificial saliva. Specimens were impacted at $20 \mathrm{mph}$ by a 0.5 -inch
\end{abstract}


diameter indenter containing a force transducer (Dynatup Model 9250 HV, Instron Corp., Canton, MA), based upon ASTM (American Society for Testing and Materials) Standard D3763. Energy absorption was determined from the area under the force-time curve during the impact event (approximately 5 or 7 millisec depending on the material). Groups were compared using ANOVA and the Tukey test. Regions near the impact site were examined with an SEM. $\underline{\text { Results: }}$ Energy absorption values, normalized to specimen thickness (mean $\pm \mathrm{SD}$ in J/mm), were: (a) Dry: EVA $(n=10) 4.73 \pm 0.27$, Proform $^{\mathrm{TM}}(n=10) 3.55 \pm 0.25$, PolyShok ${ }^{\mathrm{TM}}(n=10) 6.32 \pm 0.24$; (b) DI water: EVA $(n=$ 10) $4.82 \pm 0.40$, Pro-form ${ }^{\mathrm{TM}}(n=10) 3.78 \pm 0.33$, PolyShok ${ }^{\mathrm{TM}}(n=10) 5.87 \pm 0.38 ;(\mathrm{c})$ Artificial saliva: EVA $(n=10) 5.63 \pm 0.49$, Pro-form ${ }^{\mathrm{TM}}(n=10) 4.01 \pm 0.54$, PolyShok ${ }^{\mathrm{TM}}$ ( $n=10) 6.37 \pm 0.55$. PolyShok ${ }^{\mathrm{TM}}$ had the highest energy absorption, and conventional EVA was superior to Pro-form ${ }^{\mathrm{TM}}$. Energy absorption was significantly higher in artificial saliva than the other two media for EVA, but not for Pro-form ${ }^{\mathrm{TM}}$ and PolyShok ${ }^{\mathrm{TM}}$. Characteristic deformation patterns from impact loading were observed for each material. Conclusions: The superior energy absorption for PolyShok ${ }^{\mathrm{TM}}$ is attributed to the polyurethane additive.

KEY WORDS: preventive dentistry, dental materials, physical, biomaterials, polymers

\section{INTRODUCTION}

The use of mouthguards has long been promoted as a significant way of reducing the incidence of sports and recreational activity related injuries (1). The American Dental Association recognizes the preventive value of oro-facial protection and recommends the 
use of mouthguards in 29 sports/exercise activities (2). Mouthguards can act as a buffer from trauma and provide a degree of protection for both the mouth's soft tissues (lips, gums, and tongue) and hard tissues (teeth and alveolar bone), as well as protection from brain injuries (3). The ability to protect the mouth is highly dependent on the ability of the mouthguard to act as a shock absorber and absorb the force transmitted to the teeth (4). There are no international standards set for the materials used in the fabrication of mouthguards; however, it is important that the materials used have sufficient energy absorption capability to dissipate impact forces that occur under clinical conditions (5).

Because of their ease of fabrication and low cost, the most common mouthguards typically used are stock and mouth-formed (boil and bite), made from ethylene vinyl acetate (EVA) materials (6). An increase in the education of coaches, athletes, and parents over the years has led to a rise in custom-fabricated mouthguards. This has helped to encourage dental innovation, leading to advancements in design and materials to optimize their energy absorption characteristics.

Studies have shown that the thicker a mouthguard is, the larger the force it can withstand (7-9). Thick mouthguards, however, are not comfortable and can result in decreased ability to breathe and speak properly. Because patient comfort dictates compliance, $4 \mathrm{~mm}$ was decided upon as the optimal mouthguard thickness to allow comfort without compromising protection (7). Numerous efforts; including laminant layering, air-filled cavities, sorbathane inserts, and hard acrylic inserts, have been made to find a mouthguard design that does not need to get thicker to provide increased protection (10-14). 
There are several mechanical and physical properties that can affect the protective capability of a mouthguard, such as tensile strength, hardness, stiffness, tear strength, and water absorption. Equally, if not more important, is the ability to absorb energy and reduce forces transmitted to the teeth. There have been numerous studies over the years that evaluated the impact resistance of mouthguards and the effectiveness of different variations in their material composition by using a pendulum, an indenter, or droppedweight apparatus $(5,7,10,11,15-24)$.

The majority of in vitro tests investigating the impact resistance of mouthguard materials have been conducted in a dry environment without any regard to temperature. Because of their exposure to the oral cavity, mouthguards are subjected to varying degrees of moisture saturation as well as to a temperature that closely mimics body temperature. As the mouthguard material absorbs moisture, its mechanical properties may change and affect its ability to withstand forces. Coto et al report that EVA responded positively and showed improved mechanical response as a result of exposure to artificial saliva solution (9). Recent impact test studies by Mendel et al also suggest that mouthguard materials behave differently when conditioned in aqueous and dry environments (25-27). Meng et al also determined from differential scanning calorimetry that critical changes in EVA crystal formation occur near body temperature and could have significant effects on energy absorption potential (24).

The purpose of the present investigation was to perform additional impact tests to evaluate in greater detail the energy absorption characteristics of the three different mouthguard materials studied by Mendel et al (25-27): EVA, Pro-form ${ }^{\mathrm{TM}}$, and PolyShok ${ }^{\mathrm{TM}}$. In this investigation these materials were conditioned at body temperature in 
three different environments: dry (in ambient air), deionized water and artificial saliva. The results of this investigation will help in selection of the optimal material to fabricate mouthguards used for athletic programs at The Ohio State University and by other sports programs.

\section{MATERIALS AND METHODS}

\section{Mouthguard materials}

The three commercially available mouthguard materials previously used by Mendel et al (25-27) were selected for testing: a conventional ethylene vinyl acetate (EVA, Keystone Industries, Cherry Hill, NJ), serving as the control; Pro-form ${ }^{\mathrm{TM}}$ (Dental Resources Inc, Delano, MN), another ethylene vinyl acetate thermoplastic material; and PolyShok $^{\mathrm{TM}}$ (Sportsguard Laboratories, Kent, OH), an ethylene vinyl acetate product containing polyurethane. All materials were purchased from the manufacturers, verified to be from the same production batch, and tested as received.

\section{Material processing}

All materials were processed according to manufacturer recommendations for conventional mouthguard production. Each standard $12.7 \mathrm{~cm} \times 12.7 \mathrm{~cm} \times 4 \mathrm{~mm}$ sheet was heated at uniform temperature until there was a 3-cm droop, as verified by a wire jig, and then drawn over a master stone model of $7.5 \mathrm{~cm} \times 7.5 \mathrm{~cm} \times 2.5 \mathrm{~cm}$ dimensions representing the dental arch. After cooling for $1 \mathrm{~h}$, the sheet of material was cut into specimens of approximately $7.5 \mathrm{~cm} \times 7.5 \mathrm{~cm}$ dimensions. The starting thickness of 
approximately $4 \mathrm{~mm}$ for the as-manufactured materials decreased during the processing used to prepare the test specimens.

\section{Impact-testing procedure}

The impact properties of the molded mouthguard material samples were tested with an instrumented impact tester (Dynatup Model 9250 HV, Instron Corp, Canton, MA). The pneumatic clamping fixture of the drop-tower apparatus on the Instron machine was set with a 3.0-inch ring opening on the top and a bottom support ring with a diameter opening of approximately 1.5 inches. Stop blocks set on top of spacers were mounted on the base of the tower to arrest the downward motion of the drop weight that provided the impact loading. The impact-testing protocol was based upon ASTM Standard D3763 (28). Specimens that were conditioned in deionized water or artificial saliva at $37^{\circ} \mathrm{C}$ were removed from the liquid and immediately placed in a test chamber at $37^{\circ} \mathrm{C}$ where they were loaded at $20 \mathrm{mph}$ (miles per hour) by a 0.5 -inch diameter round tipped indenter (striker) containing a force transducer. Each impact test had a maximum duration of 10 millisec (ms). Energy absorption was determined from the area under the force-time curve during the impact event (ranging from approximately $5-7 \mathrm{~ms}$ depending on the material), using the speed of the impacting indenter. Each value of energy absorption was normalized to the measured thickness (NTT) of the specific test specimen. Results were compared using two-way ANOVA and the post hoc Tukey test. An initial power analysis from preliminary data had indicated the need for 10 specimens of each material for each condition. Ninety specimens were tested: three materials (EVA, Pro-form ${ }^{\mathrm{TM}}$, and PolyShok ${ }^{\mathrm{TM}}$ ) in three environments (dry, deionized 
water, and artificial saliva), with 10 replicate specimens for each material-environment combination. Ten specimens of each material were tested in the dry condition, and these samples were allowed to equilibrate first for $1 \mathrm{~h}$ in the $37^{\circ} \mathrm{C}$ chamber. Ten specimens of each material (EVA, Pro-form ${ }^{\mathrm{TM}}$, and PolyShok ${ }^{\mathrm{TM}}$ ) were conditioned for $1 \mathrm{~h}$ in $37^{\circ} \mathrm{C}$ deionized water and then transferred to the $37^{\circ} \mathrm{C}$ chamber for immediate testing. Ten specimens of each of the three mouthguard materials were also conditioned for $1 \mathrm{~h}$ in the $37^{\circ} \mathrm{C}$ artificial saliva solution and likewise transferred to the $37^{\circ} \mathrm{C}$ chamber for immediate testing.

\section{Scanning Electron Microscope Observations}

The three processed mouthguard materials were observed qualitatively with a scanning electron microscope (SEM) to examine the differences in surface morphology and to determine if there were any differences in the effects from exposure to the three conditioning environments. Sample SEM specimens were cut from the mouthguard materials after the specimens had been subjected to the impact tests in the three environments. These specimens were obtained from near the impact sites and at remote locations from the impact sites. Specimens were first cleaned with deionized water to remove surface contaminants, air-dried, and then sputter-coated with a thin gold- film using standard vacuum-sputter coating conditions. The coating thickness was estimated to be in 10-15 $\mathrm{nm}$ range, but was not seen on images. Photomicrographs in digital format were obtained over a range of magnifications with a scanning electron microscope (Hitachi TM-1000). 


\section{RESULTS}

\section{Impact Tests}

Figures $3.1-3.9$ present impact results at $37^{\circ} \mathrm{C}, 20 \mathrm{mph}$ and the three conditions (dry, deionized water and artificial saliva) for conventional EVA, Pro-form ${ }^{\mathrm{TM}}$ and PolyShok ${ }^{\mathrm{TM}}$. The left vertical axis provides the load (units of $\mathrm{kN}$ ) sensed by the transducer as a function of time in milliseconds on the horizontal axis. These plots show that the load first increases and then decreases with time during the impact event. The right vertical axis provides the resulting energy absorption [units of $\mathrm{J}$ (Joules)], obtained from the area under the load-time curve, using the distance moved by the striker per unit time. These plots show that the energy absorption increases to a maximum level (appearing as a plateau) during the impact event. The duration of the impact event was considered to be the time interval during which the impact energy absorption for the test specimen reached this constant level. For EVA and Pro-form ${ }^{\mathrm{TM}}$, energy absorption leveled off within approximately 5 ms. The energy absorption for PolyShok ${ }^{\mathrm{TM}}$, however, did not reach a constant level until about 7 ms. The horizontal axes in Figs. $3.1-3.9$ have been terminated at these respective time periods, as indicated by the vertical lines with diamond symbols at the top and bottom. 


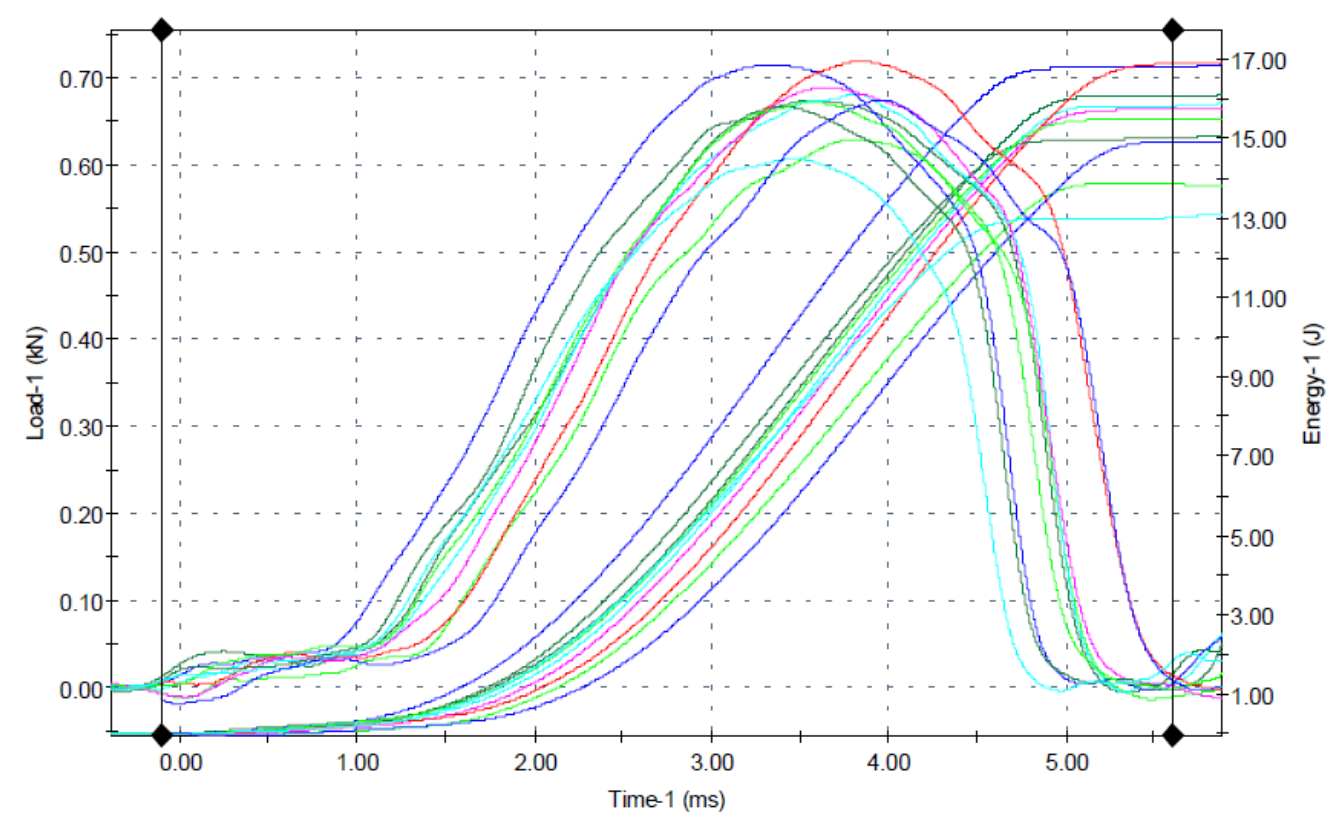

Figure 3.1 Impact test results at $20 \mathrm{mph}$ for 10 conventional EVA specimens that had been conditioned for $1 \mathrm{~h}$ in a dry environment at $37^{\circ} \mathrm{C}$ and then tested at $37^{\circ} \mathrm{C}$. 


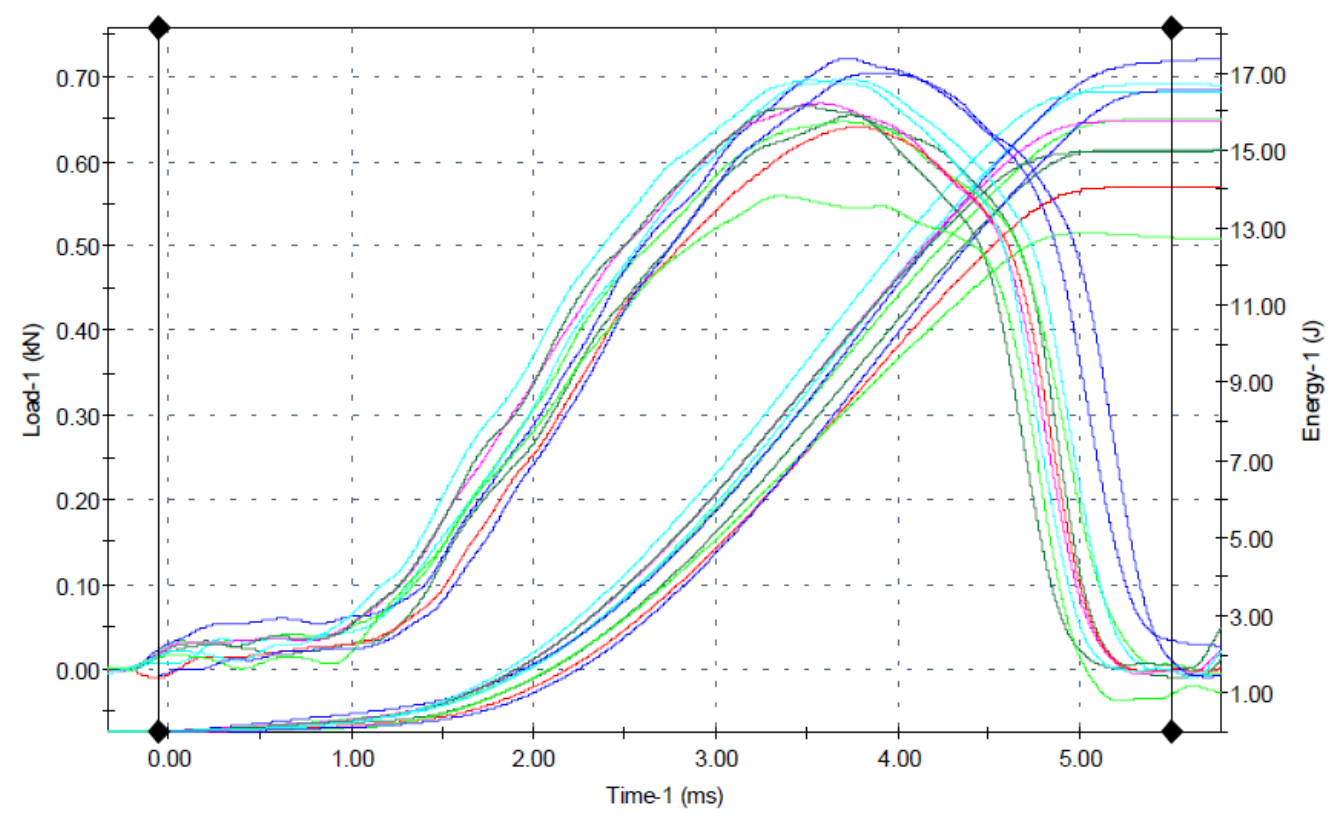

Figure 3.2 Impact test results at $20 \mathrm{mph}$ for 10 conventional EVA specimens that had been conditioned for $1 \mathrm{~h}$ in deionized water at $37^{\circ} \mathrm{C}$ and then tested at $37^{\circ} \mathrm{C}$. 


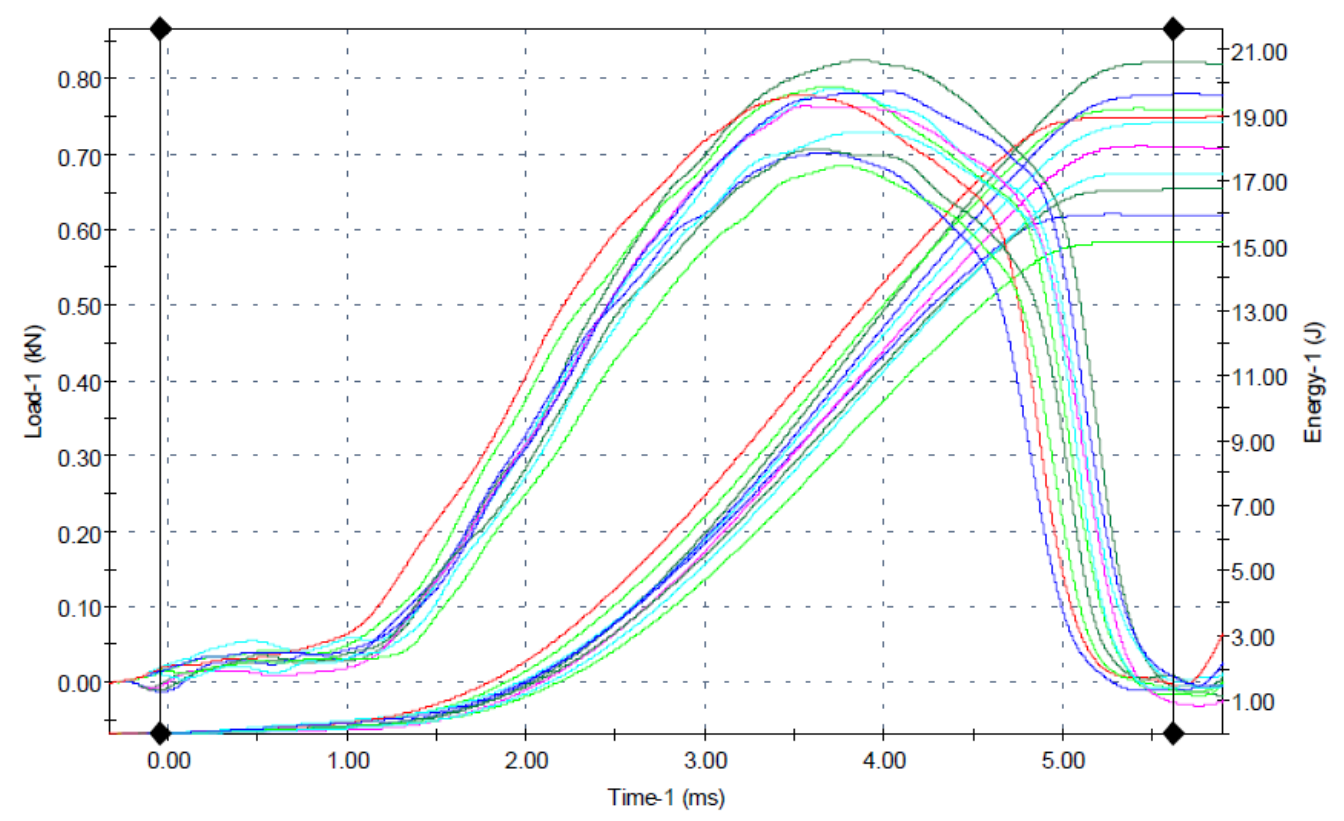

Figure 3.3 Impact test results at $20 \mathrm{mph}$ for 10 conventional EVA specimens that had been conditioned for $1 \mathrm{~h}$ in artificial saliva at $37^{\circ} \mathrm{C}$ and then tested at $37^{\circ} \mathrm{C}$. 


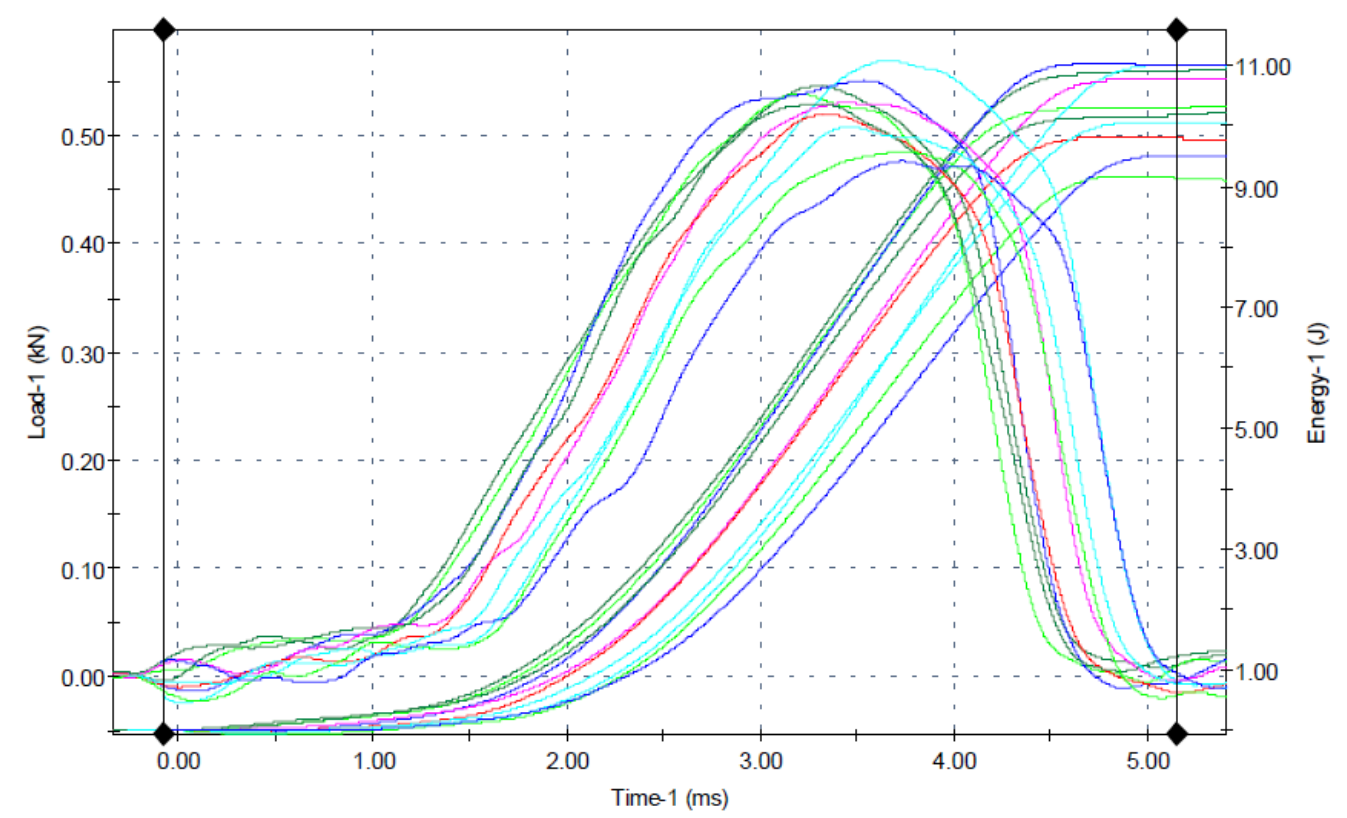

Figure 3.4 Impact test results at $20 \mathrm{mph}$ for 10 Pro-form ${ }^{\mathrm{TM}}$ specimens that had been conditioned for $1 \mathrm{~h}$ in a dry environment at $37^{\circ} \mathrm{C}$ and then tested at $37^{\circ} \mathrm{C}$. 


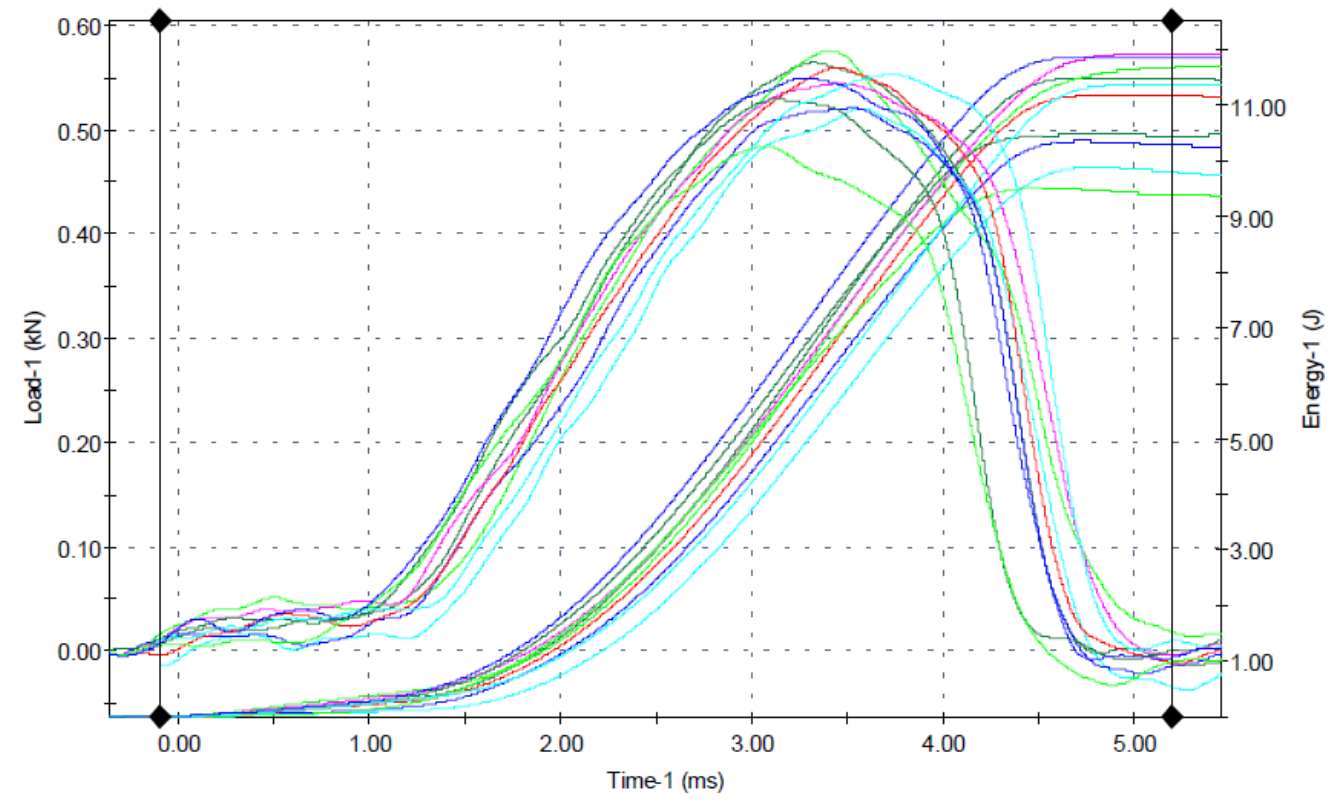

Figure 3.5 Impact test results at $20 \mathrm{mph}$ for 10 Pro-form ${ }^{\mathrm{TM}}$ specimens that had been conditioned for $1 \mathrm{~h}$ in deionized water at $37^{\circ} \mathrm{C}$ and then tested at $37^{\circ} \mathrm{C}$. 


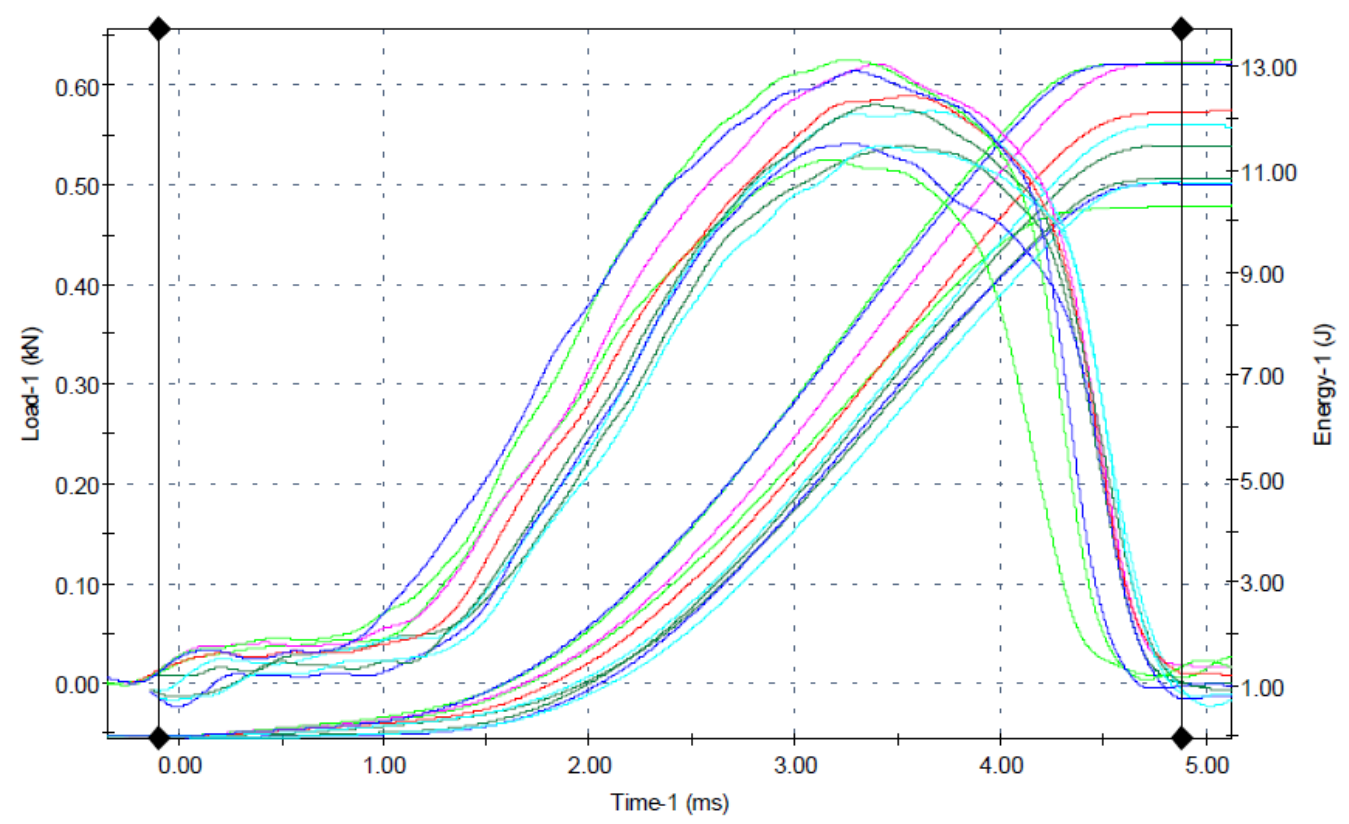

Figure 3.6 Impact test results at $20 \mathrm{mph}$ for 10 Pro-form ${ }^{\mathrm{TM}}$ specimens that had been conditioned for $1 \mathrm{~h}$ in artificial saliva at $37^{\circ} \mathrm{C}$ and then tested at $37^{\circ} \mathrm{C}$. 


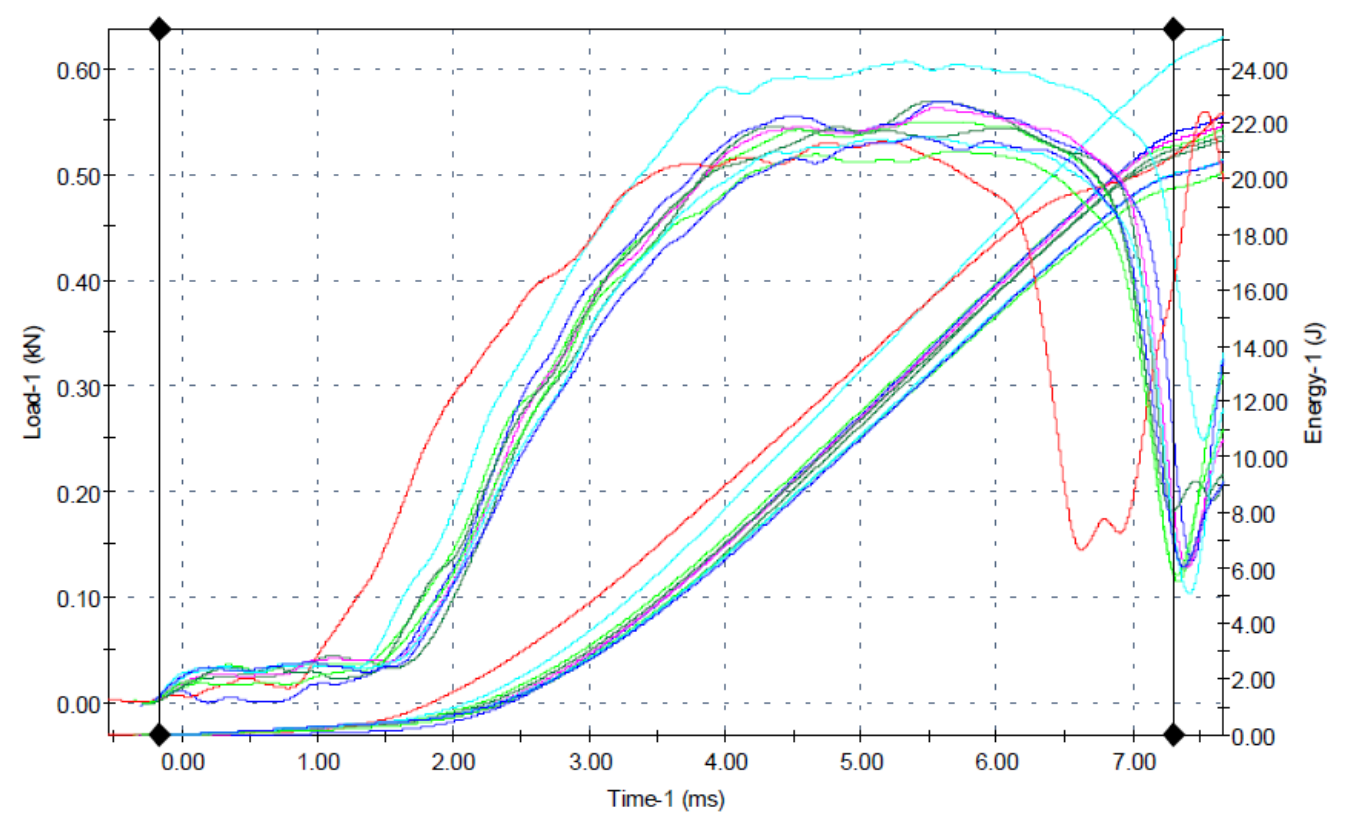

Figure 3.7 Impact test results at $20 \mathrm{mph}$ for 10 PolyShok $^{\mathrm{TM}}$ specimens that had been conditioned for $1 \mathrm{~h}$ in a dry environment at $37^{\circ} \mathrm{C}$ and then tested at $37^{\circ} \mathrm{C}$. 




Figure 3.8 Impact test results at $20 \mathrm{mph}$ for 10 PolyShok $^{\mathrm{TM}}$ specimens that had been conditioned for $1 \mathrm{~h}$ in deionized water at $37^{\circ} \mathrm{C}$ and then tested at $37^{\circ} \mathrm{C}$. 




Figure 3.9 Impact test results at $20 \mathrm{mph}$ for 10 PolyShok $^{\mathrm{TM}}$ specimens that had been conditioned for $1 \mathrm{~h}$ in artificial saliva at $37^{\circ} \mathrm{C}$ and then tested at $37^{\circ} \mathrm{C}$. 
Table 3.1 summarizes the total energy absorption at approximately 5 or $7 \mathrm{~ms}$ (depending on the right-hand vertical lines in Figures 3.1 - 3.9). The energy absorption values were normalized to specimen thickness (NTT) for the three mouthguard materials tested in the dry, wet, and artificial saliva conditions at $37^{\circ} \mathrm{C}$, and for an impact speed of $20 \mathrm{mph}$, using 3.0-inch diameter top and 1.5-inch bottom support rings. The NTT energy absorption values (mean \pm SD in J/mm), were: (a) Dry: EVA $(n=10) 4.73 \pm 0.27$, Pro-form ${ }^{\mathrm{TM}}(n=10) 3.55 \pm 0.25$, PolyShok ${ }^{\mathrm{TM}}(n=10) 6.32 \pm 0.24$; (b) DI water: EVA $(n=10) 4.82 \pm 0.40$, Pro-form ${ }^{\mathrm{TM}}(n=10) 3.78 \pm 0.33$, PolyShok $^{\mathrm{TM}}(n=10) 5.87 \pm 0.38$; (c) Artificial saliva: EVA $(n=10) 5.63 \pm 0.49$, Pro-form ${ }^{\mathrm{TM}}(n=10) 4.01 \pm 0.54$, $\operatorname{PolyShok}^{\mathrm{TM}}(n=10) 6.37 \pm 0.55$.

\begin{tabular}{|l|c|c|c|c|}
\hline Material & Specimens $(\mathrm{n})$ & Condition & $\begin{array}{c}\text { Mean NTT energy at 5 - 7 ms } \\
(\mathrm{J} / \mathrm{mm})\end{array}$ & SD $(\mathrm{J} / \mathrm{mm})$ \\
\hline EVA & 10 & Dry & $4.730(5 \mathrm{~ms})$ & 0.270 \\
\hline EVA & 10 & Wet & $4.816(5 \mathrm{~ms})$ & 0.401 \\
\hline EVA & 10 & Saliva & $5.628(5 \mathrm{~ms})$ & 0.492 \\
\hline & & & & \\
\hline Pro-form & & $3.550(5 \mathrm{~ms})$ & 0.253 \\
\hline Pro-form $^{\mathrm{TM}}$ & 10 & Dry & $3.781(5 \mathrm{~ms})$ & 0.329 \\
\hline Pro-form $^{\mathrm{TM}}$ & 10 & Wet & $4.008(5 \mathrm{~ms})$ & 0.543 \\
\hline & 10 & Saliva & & \\
\hline PolyShok $^{\mathrm{TM}}$ & 10 & Dry & $6.316(7 \mathrm{~ms})$ & 0.237 \\
\hline PolyShok $^{\mathrm{TM}}$ & 10 & Wet & $5.867(7 \mathrm{~ms})$ & 0.376 \\
\hline PolyShok & & Saliva & $6.368(7 \mathrm{~ms})$ & 0.551 \\
\hline
\end{tabular}

Table 3.1 Results for total energy, normalized to thickness (NTT), for the three mouthguard materials tested in the three conditions at $37^{\circ} \mathrm{C}$ at an impact speed of $20 \mathrm{mph}$, using 3-inch diameter top and 1.5 inch bottom support rings. Before testing, specimens were conditioned in their respective environment for $1 \mathrm{~h}$ at $37^{\circ} \mathrm{C}$.

Statistical comparisons were made between the different materials and environments, using two-way ANOVA and the Tukey test. With three different materials and three different conditioning environments, the number of comparisons was high. 
Table 3.2 lists the results of ANOVA and the Tukey test, with adjusted P values in the right column. All results $(*)$ with an adjusted $\mathrm{P}$ value $<.05$ were considered significant.

\begin{tabular}{|c|c|c|c|c|c|c|}
\hline Material & Environment & vs. & Material & Environment & $\operatorname{Pr}>[\mathrm{t}]$ & Adjusted P \\
\hline & Dry & & & $\mathrm{DI} \mathrm{H}_{2} \mathrm{O}$ & 0.6530 & 0.894 \\
\hline & Dry & & & Saliva & $<.0001$ & $<.0001^{*}$ \\
\hline & $\mathrm{DI} \mathrm{H}_{2} \mathrm{O}$ & & & Saliva & $<.0001$ & $<.0001 *$ \\
\hline EVA & Dry & & EVA & $\mathrm{H} 20$ & 0.6132 & 0.9999 \\
\hline EVA & Dry & & EVA & Saliva & $<.0001$ & $<.0001 *$ \\
\hline EVA & Dry & & PRO & Dry & $<.0001$ & $<.0001^{*}$ \\
\hline EVA & Dry & & PRO & $\mathrm{DI} \mathrm{H}_{2} \mathrm{O}$ & $<.0001$ & $<.0001 *$ \\
\hline EVA & Dry & & PRO & Saliva & $<.0001$ & $0.0018^{*}$ \\
\hline EVA & Dry & & $\mathrm{POL}$ & Dry & $<.0001$ & $<.0001^{*}$ \\
\hline EVA & Dry & & POL & $\mathrm{DI} \mathrm{H}_{2} \mathrm{O}$ & $<.0001$ & $<.0001 *$ \\
\hline EVA & Dry & & POL & Saliva & $<.0001$ & $<.0001 *$ \\
\hline EVA & $\mathrm{DI} \mathrm{H}_{2} \mathrm{O}$ & & EVA & Saliva & $<.0001$ & $0.0003 *$ \\
\hline EVA & $\mathrm{DI} \mathrm{H}_{2} \mathrm{O}$ & & PRO & Dry & $<.0001$ & $<.0001 *$ \\
\hline EVA & $\mathrm{DI} \mathrm{H}_{2} \mathrm{O}$ & & PRO & $\mathrm{DI} \mathrm{H}_{2} \mathrm{O}$ & $<.0001$ & $<.0001 *$ \\
\hline EVA & $\mathrm{DI} \mathrm{H}_{2} \mathrm{O}$ & & PRO & Saliva & $<.0001$ & $0.0003 *$ \\
\hline EVA & $\mathrm{DI} \mathrm{H}_{2} \mathrm{O}$ & & POL & Dry & $<.0001$ & $<.0001 *$ \\
\hline EVA & $\mathrm{DI} \mathrm{H}_{2} \mathrm{O}$ & & POL & $\mathrm{DI} \mathrm{H}_{2} \mathrm{O}$ & $<.0001$ & $<.0001 *$ \\
\hline EVA & $\mathrm{DI} \mathrm{H}_{2} \mathrm{O}$ & & POL & Saliva & $<.0001$ & $<.0001 *$ \\
\hline EVA & Saliva & & PRO & Dry & $<.0001$ & $<.0001 *$ \\
\hline EVA & Saliva & & PRO & $\mathrm{DI} \mathrm{H}_{2} \mathrm{O}$ & $<.0001$ & $<.0001 *$ \\
\hline EVA & Saliva & & PRO & Saliva & $<.0001$ & $<.0001 *$ \\
\hline EVA & Saliva & & POL & Dry & 0.0001 & $0.0036^{*}$ \\
\hline EVA & Saliva & & POL & $\mathrm{DI} \mathrm{H}_{2} \mathrm{O}$ & 0.1636 & 0.8924 \\
\hline EVA & Saliva & & POL & Saliva & $<.0001$ & $0.0012 *$ \\
\hline PRO & Dry & & PRO & $\mathrm{DI} \mathrm{H}_{2} \mathrm{O}$ & 0.1796 & 0.9114 \\
\hline PRO & Dry & & PRO & Saliva & 0.0086 & $0.0174 *$ \\
\hline PRO & Dry & & POL & Dry & $<.0001$ & $<.0001 *$ \\
\hline PRO & Dry & & POL & $\mathrm{DI} \mathrm{H}_{2} \mathrm{OO}$ & $<.0001$ & $<.0001 *$ \\
\hline PRO & Dry & & POL & Saliva & $<.0001$ & $<.0001 *$ \\
\hline PRO & $\mathrm{DI} \mathrm{H}_{2} \mathrm{O}$ & & PRO & Saliva & 0.1847 & 0.9167 \\
\hline PRO & $\mathrm{DI} \mathrm{H}_{2} \mathrm{O}$ & & POL & Dry & $<.0001$ & $<.0001 *$ \\
\hline PRO & $\mathrm{DI} \mathrm{H}_{2} \mathrm{O}$ & & POL & $\mathrm{DI} \mathrm{H}_{2} \mathrm{O}$ & $<.0001$ & $<.0001 *$ \\
\hline PRO & $\mathrm{DI} \mathrm{H}_{2} \mathrm{O}$ & & POL & Saliva & $<.0001$ & $<.0001 *$ \\
\hline PRO & Saliva & & POL & Dry & $<.0001$ & $<.0001 *$ \\
\hline PRO & Saliva & & POL & $\mathrm{DI} \mathrm{H}_{2} \mathrm{O}$ & $<.0001$ & $<.0001 *$ \\
\hline PRO & Saliva & & POL & Saliva 1 & $<.0001$ & $<.0001 *$ \\
\hline POL & Dry & & POL & $\mathrm{DI} \mathrm{H}_{2} \mathrm{O}$ & 0.0099 & 0.1857 \\
\hline POL & Dry & & POL & Saliva & 0.7599 & 1.000 \\
\hline POL & $\mathrm{DI} \mathrm{H}_{2} \mathrm{O}$ & & POL & Saliva & 0.0042 & 0.0922 \\
\hline
\end{tabular}

Table 3.2 Summary of statistical comparisons for energy absorption of three mouthguard materials in three testing environments. 
The first three rows in Table 3.2 show a comparison among 3 three conditioning environments, for which the results for all 3 mouthguard materials have been combined. It can be seen that there was no significant difference for the three mean values of energy absorption for each material when conditioned in air or deionized water. The remaining rows present the statistical results for all of the pair-wise comparisons among the 3 materials and conditioning environments.

\section{SEM Study}

Representative areas near the impact zone and away from the impact zone were selected and viewed. After extensive observations, SEM was unable to find definitive differences for each material when comparing impact sites from specimens conditioned in any of the three environments (dry, water and artificial saliva). All three mouthguard materials appeared to be characterized by tearing to varying extent during the impact loading. Figure 3.10 shows a sample of EVA conditioned in a dry environment. The pattern of tearing shows a classic river pattern of fracture with secondary cracks branching from primary cracks. Figure 3.11 shows a sample of Pro-form ${ }^{\mathrm{TM}}$ conditioned in de-ionized water and Figure 3.12 shows a sample PolyShok ${ }^{\mathrm{TM}}$ conditioned in artificial saliva. Pro-form ${ }^{\mathrm{TM}}$ and PolyShok ${ }^{\mathrm{TM}}$ were both characterized to be tearing as the major feature of impact fracture. 


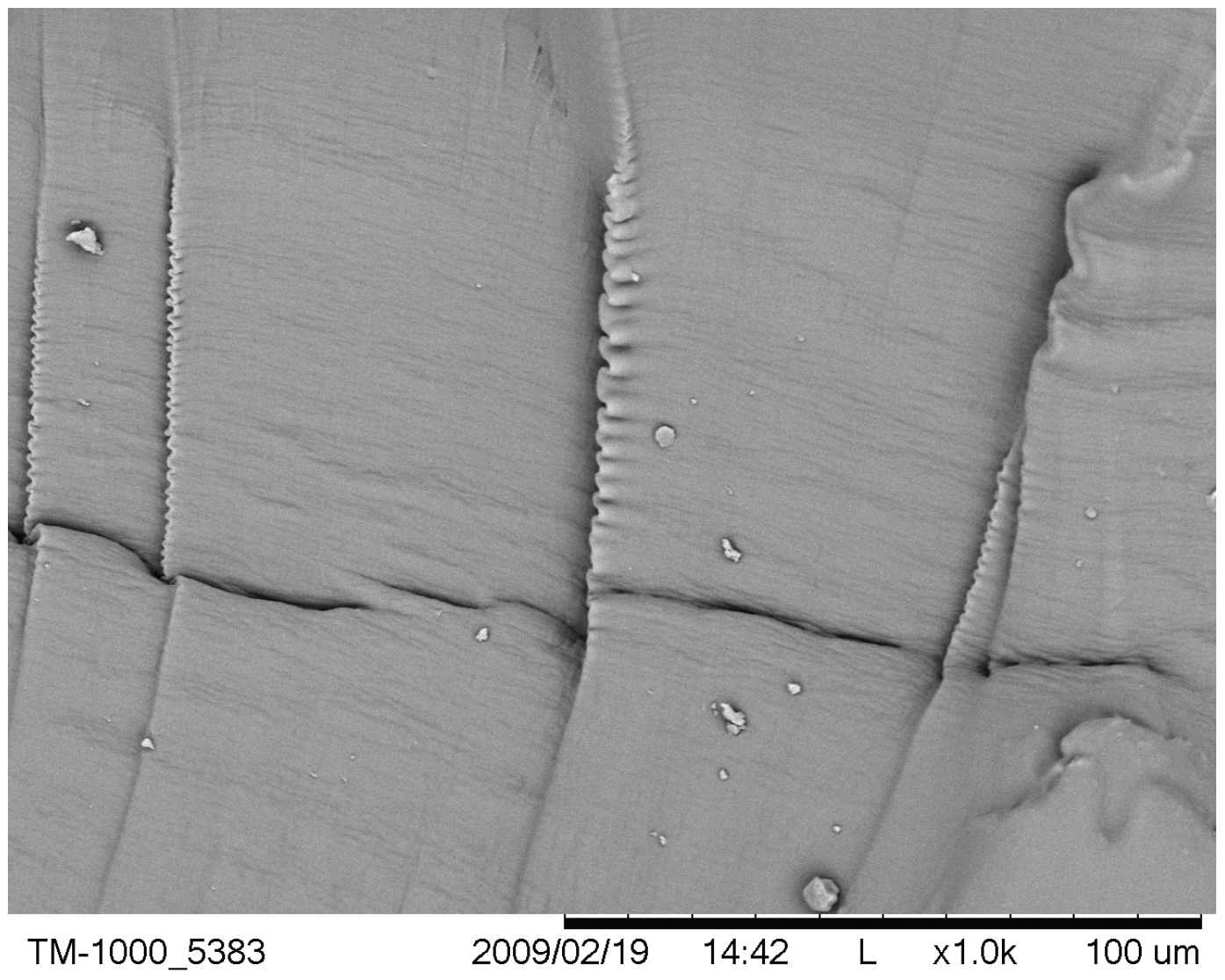

Figure 3.10 SEM image near the impact site of EVA sample after conditioning for $1 \mathrm{~h}$ at $37^{\circ} \mathrm{C}$ in dry environment and loading at $20 \mathrm{mph}$. 


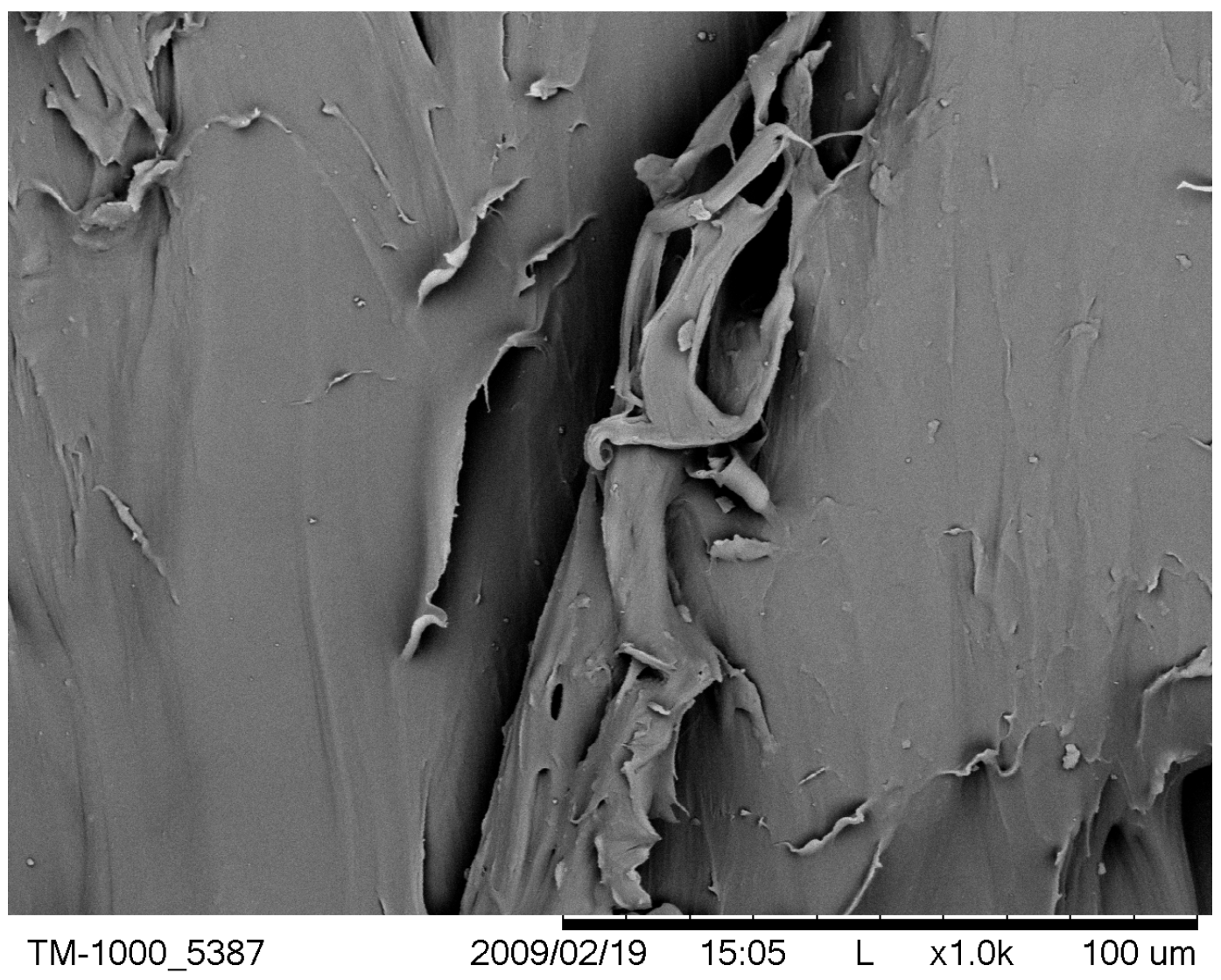

Figure 3.11 SEM image near the impact site of Pro-form ${ }^{\mathrm{TM}}$ sample after conditioning for $1 \mathrm{~h}$ at $37^{\circ} \mathrm{C}$ in deionized water and loading at $20 \mathrm{mph}$. 


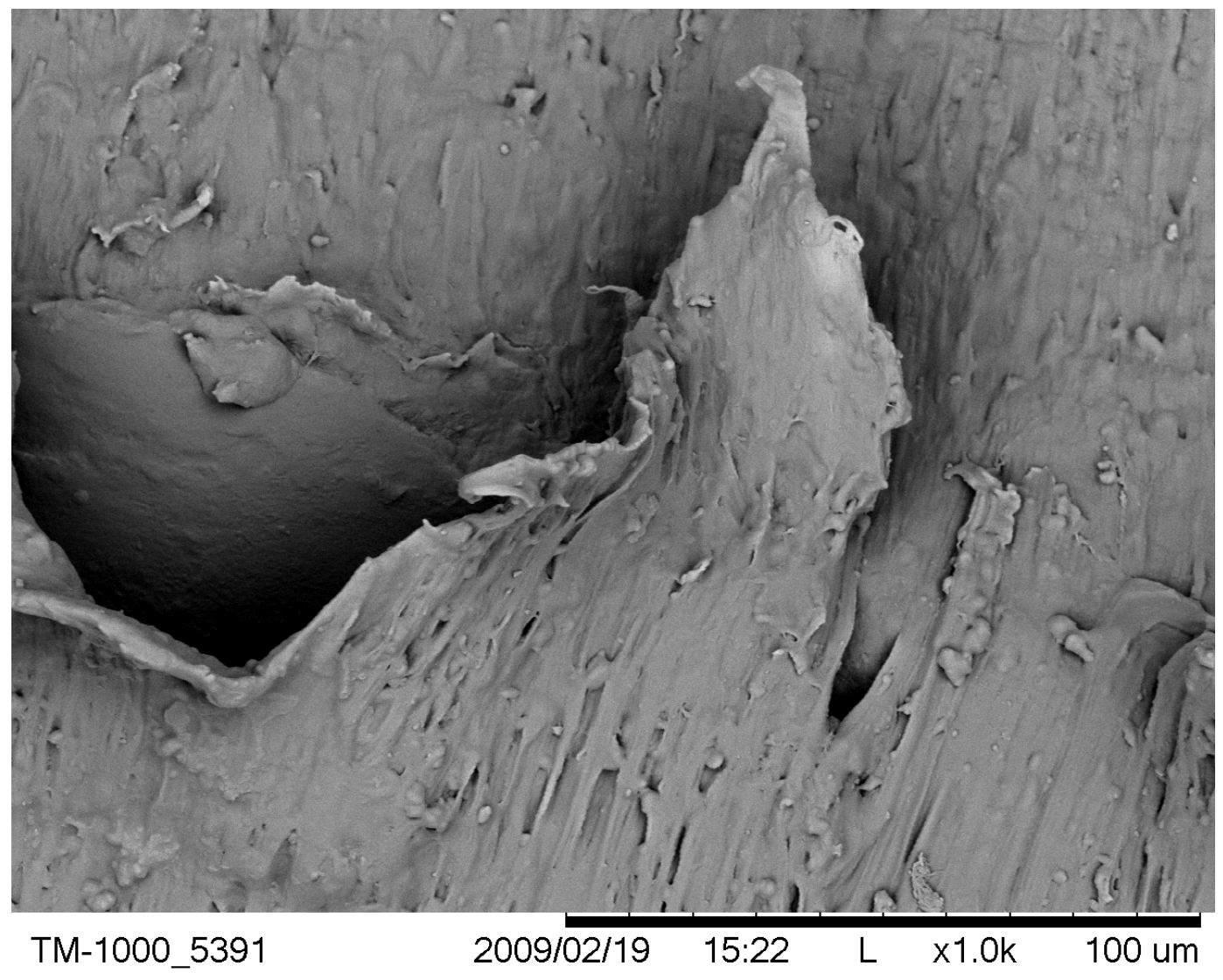

Figure 3.12 SEM image near the impact site of PolyShok ${ }^{\mathrm{TM}}$ sample after conditioning for $1 \mathrm{~h}$ at $37^{\circ}$ in saliva substitute and loading at $20 \mathrm{mph}$. 


\section{DISCUSSION}

Because of the difficulty in carrying out studies in a clinical situation, impact testing of mouthguards is typically done in vitro. In order to compare mouthguard materials under more clinically relevant conditions, Mendel et al previously conducted impact tests in which specimens were conditioned in deionized water (27). Results of their study indicated that there may be differences in energy absorption due to the water conditioning (27). The present study looks further into possible environmental differences that an artificial saliva conditioner might have on the impact resistance of

materials, and includes a third group of test samples that were conditioned and tested in artificial saliva. Admittedly, the sample groups for the deionized water and artificial saliva groups were only conditioned for $1 \mathrm{~h}$ in these media, but this time period was considered to relevant to typical use conditions by athletes following a period of mouthguard storage at dry (ambient) conditions. While the artificial saliva medium was chosen to simulate the oral environment, we recognize that the more complex composition of oral saliva and presence of oral bacteria are factors for further study. Comparison of two previous studies by Mendel et al, using the same protocol and materials suggested that impact test performance could vary substantially between different batches of the same material $(26,27)$. In the present study each mouthguard material was verified by each manufacturer as belonging to the same batch, to avoid any inter-batch variation from affecting the results. Figures 3.1 - 3.9 and Table 3.1 show that each data set was very uniform with small standard deviations, thus ruling out any intramaterial differences. 
The impact speed of various objects in sports injuries can vary significantly. Although speeds of Injuries can Hockey pucks can reach speed of up to $120 \mathrm{mph}$ while When Mendel et al previously carried out impact tests in dry and wet environments, the impact energy absorption of PolyShok ${ }^{\mathrm{TM}}$ was observed to be significantly greater than that for EVA and Pro-form ${ }^{\mathrm{TM}}$ (27). Table 3.2 shows that in the present study PolyShok ${ }^{\mathrm{TM}}$ again had significantly higher impact energy absorption than EVA and Pro-form ${ }^{\mathrm{TM}}$, regardless of the conditioning procedure. This is particularly important because conditions of clinical application are not always the same. Polyshok, however, will perform the same whether the impact happens right when the athlete puts in the mouthguard or after it has conditioned in the mouth for a period of time. Table 3.2 also shows that EVA and Pro-form ${ }^{\mathrm{TM}}$ absorbed significantly more impact energy after saliva conditioning than when dry. In a small sample, no difference in weight was observed before and after conditioning, ruling out saliva absorption, so a future study is necessary to determine the origin of this behavior. The present results for EVA are in agreement with those of Coto et al (9), who found that mechanical properties for EVA improved after conditioning in artificial saliva. In contrast, the present study (Table 3.2) indicated that there was no significant difference in impact energy absorption of PolyShok ${ }^{\mathrm{TM}}$ with the three different conditioning media.

Previous SEM observations have shown that PolyShok ${ }^{\mathrm{TM}}$ has a nodular surface with the appearance of "air pockets" (24). Figure 3.12 also shows a similar bead-like appearance of the polyurethane particles on the fracture surfaces of Polyshok ${ }^{\mathrm{TM}}$. All three mouthguard materials appeared to be characterized by tearing to varying extent during the impact loading. This tearing is expected to be correlated with fine-scale polymer 
microstructure, but further study is required to provide details. The superior impact energy absorption of PolyShok ${ }^{\mathrm{TM}}$ is assumed to be due in large part to these polyurethane filler particle additives, since the general nature of the impact failure process was similar for all three mouthguard materials. The absence of major differences in the impact fracture surfaces for each material with the three conditioning media suggests that their effects on the polymer structure are at the molecular level and not directly detectable with the SEM.

In addition to its greater ability to absorb energy, PolyShok ${ }^{\mathrm{TM}}$ has an additional valuable property compared to EVA and Pro-form ${ }^{\mathrm{TM}}$. PolyShok ${ }^{\mathrm{TM}}$ sheets have the unique ability of self-lamination using vacuum-formed pressure, instead of requiring expensive high heat and pressure machines. This provides three distinct advantages: (1) The general availability of vacuum-forming equipment in general dental offices means that custom mouthguards can be readily and easily fabricated. (2) It is easy to compensate for loss of individual sheet thickness from processing by combining multiple sheets to obtain a mouthguard of the desired thickness. (3) It allows individual customization in appearance as decorative items can be placed on the first layer and covered by a second clear laminated top layer. By improving the mouthguard appearance, compliance is increased, especially in younger athletes.

\section{CONCLUSIONS}

When impacted at $20 \mathrm{mph}$ and $37^{\circ} \mathrm{C}$ using ASTM Standard D 3763 methodology, PolyShok ${ }^{\mathrm{TM}}$ was the most energy absorbent material in all three environments, most 
likely due to its polyurethane additive. EVA was also significantly more impact resistant than ProForm ${ }^{\mathrm{TM}}$ in all three environments. EVA and ProForm ${ }^{\mathrm{TM}}$ performed significantly better after saliva conditioning than dry or water conditioned, but Polyshok ${ }^{\mathrm{TM}}$ did not show any difference in energy absorption when conditioned in any of the three environments.

\section{REFERENCES}

1. Watts G, Woolard A, Singer CE. Functional mouth protectors for contact sports. JADA 1954;49:7-11.

2. American Dental Association. For the dental patient. The importance of using mouthguards. Tips for keeping your smile safe. J Am Dent Assoc 2004;135(7):1061.

3. Knapik J, Marshall S, Lee R, Darakjy S, Jones S, Mitchener T, et al. Mouthguards in sport activities: history, physical properties and injury prevention effectiveness. Sports Med 2007;37:117-44.

4. Craig RG, Godwin WC. Properties of athletic mouth protectors and materials. J Oral Rehab 2002;29:146-50.

5. Tran D, Cooke M, Newsome P. Laboratory evaluation of mouthguard material. Dent Traumatol 2001;17:260-5.

6. Padilla R, Dorney B, Balikov S. Prevention of oral injuries. J Calif Dent Assoc 1996;24(3):30-6.

7. Westerman B, Stringfellow PM, Eccleston JA. EVA mouthguards: how thick should they be? Dental Traumatol 2002;18:24-7.

8. Maeda M, Takeda T, Nakajima K, Shibusawa M, Kurokawa K, Shimada A, et al. In search of necessary mouthguard thickness. Part 1: From the viewpoint of shock absorption ability. Nihon Hotetsu Shika Gakkai Zasshi 2008;52:211-9.

9. Coto N, Brito e Dias R, Costa R, Antoniazzi T, de Carvalho E. Mechanical behavior of ethylene vinyl acetate copolymer (EVA) used for fabrication of mouthguards and interocclusal splints. Braz Dent J 2007;18:324-8. 
10. Bulsara Y, Matthew I. Forces transmitted through a laminated mouthguard material with a Sorbothane insert. Endod Dent Traumatol 1998;14:45-7.

11. Bemelmanns P, Pfeiffer P. Shock absorption capacities of mouthguards in different types and thicknesses. Int J Sports Med 2001;22:149-53.

12. Westerman B, Stringfellow P, Eccleston J. Beneficial effects of air inclusions on the performance of ethylene vinyl acetate (EVA) mouthguard material. Br J Sports Med 2002;36:51-3.

13. Westerman B, Stringfellow P, Eccleston J. The effect on energy absorption of hard inserts in laminated EVA mouthguards. Aust Dent J 2000;45:21-3.

14. Oikarinen K, Salonen M. Introduction to four custom-made mouth protectors constructed of single and double layers for activists in contact sports. Endod Dent Traumatol 1993;9:19-24.

15. Bishop BM, Davies EH, von Fraunhofer JA. Materials for mouth protectors. J Prosthet Dent 1985; 53: 256-61.

16. Craig RG, Godwin WC. Physical properties of materials for custom-made mouth protectors. J Mich State Dent Assoc 1967;49:34-40.

17. Going RE, Loehman RE, Chan MS. Mouthguard materials: their physical and mechanical properties. JADA 1974;89:132-8.

18. Westerman B, Stringfellow PM, Eccleston JA. An improved mouthguard material. Aust Dent J 1997;42:189-91.

19. Westerman B, Stringfellow PM, Eccleston JA. Forces transmitted through EVA mouthguard materials of different types and thickness. Aust Dent J 1995;40:389-91.

20. Duhaime C, Whitmyer C, Butler R, Kuban B. Comparison of forces transmitted through different EVA mouthguards. Dent Traumatol 2006;22:186-92.

21. Johnston T, Messer LB. An in vitro study of the efficacy of mouthguard protection for dentoalveolar injuries in deciduous and mixed dentitions. Endod Dent Traumatol 1996;12:277-85.

22. Takeda T, Ishigami K, Shintaro K, Nakajima K, Shimada A, Regner CW. The influence of impact object characteristics on impact force and force absorption of mouthguard material. Dent Traumatol 2004;20:12-20.

23. Guevara PH, Hondrum SO, Reichl RB. A comparison of commercially available mouthguards and a custom mouthguard. Gen Dent 2001;49: 402-6. 
24. Meng FH, Schricker SR, Brantley WA, Mendel DA, Rashid RG, Fields HW, et al. Differential scanning calorimetry (DSC) and temperature-modulated DSC study of three mouthguard materials. Dent Mater 2007;23:1492-9.

25. Mendel D, Sanli Y, Brantley WA, Rashid RG, Harrell SL, Grentzer TH. Energy absorption of three mouthguard materials at higher impact speed. J Dent Res 2004;83 (Special Issue A):CD-ROM. [Abstract No. 565.]

26. Mendel D, Sanli Y, Brantley WA, Rashid RG, Harrell SL, Grentzer TH. Energy absorption characteristics of three mouthguard materials. J Dent Res 2005;84 (Special Issue A):CD-ROM. [Abstract No. 420].

27. Mendel DA, Ucar Y, Brantley WA, Rashid RG, Harrell SL, Grentzer TH. Impact energy absorption of three mouthguard materials in an aqueous environment. Dent Traumatol 2009;25:130-5.

28. Standard test method for high speed puncture properties of plastics using load and displacement sensors. ASTM Standard D 3763-98, June 1998. 


\section{CHAPTER 4}

\section{GENERAL CONCLUSIONS}

The findings of this study have a significant impact and application on the clinical use of mouthguards. The importance of mouthguard use has previously been set; they significantly reduce the incidence of sports and recreational related orofacial injuries. A major factor in their level of protection is the ability to absorb impact forces. The results of this study show that when impacted at $20 \mathrm{mph}$ and $37^{\circ} \mathrm{C}$ using ASTM Standard D 3763 methodology, PolyShok ${ }^{\mathrm{TM}}$ was the most energy absorbent material in all three environments, most likely due to its polyurethane additive. EVA was also significantly more impact resistant than ProForm ${ }^{\mathrm{TM}}$ in all three environments. EVA and ProForm ${ }^{\mathrm{TM}}$ performed significantly better after saliva conditioning than dry or water conditioned, but Polyshok ${ }^{\mathrm{TM}}$ didn't show any difference in energy absorption when conditioned in any of the three environments.

In addition to its greater ability to absorb energy, PolyShok ${ }^{\mathrm{TM}}$ has an additional valuable property compared to EVA and Pro-form ${ }^{\mathrm{TM}}$. PolyShok ${ }^{\mathrm{TM}}$ sheets have the unique ability of self-lamination using vacuum-formed pressure, instead of requiring expensive high heat and pressure machines. This provides three distinct advantages: (1) The general availability of vacuum-forming equipment in general dental offices means that custom mouthguards can be readily and easily fabricated. (2) It is easy to compensate for loss of 
individual sheet thickness from processing by combining multiple sheets to obtain a mouthguard of the desired thickness. (3) It allows individual customization in appearance as decorative items can be placed on the first layer and covered by a second clear laminated top layer. By improving the mouthguard appearance, compliance is increased, especially in younger athletes. 


\section{LIST OF REFERENCES}

1. Watts G, Woolard A, Singer CE. Functional mouth protectors for contact sports. JADA 1954; 49: 7-11.

2. American Dental Association. For the dental patient. The importance of using mouthguards. Tips for keeping your smile safe. J Am Dent Assoc 2004;135(7):1061.

3. Knapik J, Marshall S, Lee R, Darakjy S, Jones S, Mitchener T, et al. Mouthguards in sport activities: history, physical properties and injury prevention effectiveness. Sports Med 2007;37:117-44.

4. Craig RG, Godwin WC. Properties of athletic mouth protectors and materials. J Oral Rehab 2002; 29: 146-50.

5. Padilla R, Dorney B, Balikov S. Prevention of oral injuries. J Calif Dent Assoc 1996;24(3):30-6.

6. Types of athletic mouthguards. Sports Dentistry Online Web site. Available at: http://www.sportsdentistry.com/mouthguards.html. Accessed November 6, 2007.

7. Tran D, Cooke M, Newsome P. Laboratory evaluation of mouthguard material. Dent Traumatol 2001;17(6):260-5.

8. Sperling LH. Introduction to physical polymer science. 2nd ed. New York: John Wiley and Sons; 1992. p. 1-65, 303-82.

9. Rosen SL. Fundamental principles of polymeric materials. 2nd ed. New York: JohnWiley and Sons; 1993. p. 9-52, 103-19.

10. Bishop BM, Davies EH, von Fraunhofer JA. Materials for mouth protectors. J Prosthet Den 1985; 53: 256-61.

11. Craig RG, Godwin WC. Physical properties of materials for custom-made mouth protectors. J Mich State Dent Assoc 1967; 49: 34-40.

12. Going RE, Loehman RE, Chan MS. Mouthguard materials: their physical and mechanical properties. JADA 1974; 89: 132-8. 
13. Westerman B, Stringfellow PM, Eccleston JA. EVA mouthguards: how thick should they be? Dental Traumatol 2002;18:24-7.

14. Westerman B, Stringfellow PM, Eccleston JA. An improved mouthguard material. Aust Dent J 1997;42:189-91.

15. Meng FH, Schricker SR, Brantley WA, Mendel DA, Rashid RG, Fields HW, et al. Differential scanning calorimetry (DSC) and temperature-modulated DSC study of three mouthguard materials. Dent Mater. 2007;23(12):1492-1499.

16. Westerman B, Stringfellow PM, Eccleston JA. Forces transmitted through EVA mouthguard materials of different types and thickness. Aust Dent J 1995;40:389-91.

17. Bulsara Y, Matthew I. Forces transmitted through a laminated mouthguard material with a Sorbothane insert. Endod Dent Traumatol 1998;14(1):45-7.

18. Duhaime C, Whitmyer C, Butler R, Kuban B. Comparison of forces transmitted through different EVA mouthguards. Dent Traumatol 2006;22(4):186-92.

19. Bemelmanns P, Pfeiffer P. Shock absorption capacities of mouthguards in different types and thicknesses. Int J Sports Med 2001;22:149-53.

20. Johnston T, Messer LB. An in vitro study of the efficacy of mouthguard protection for dentoalveolar injuries in deciduous and mixed dentitions. Endod Dent Traumatol 1996;12:277-85.

21. Takeda T, Ishigami K, Shintaro K, Nakajima K, Shimada A, Regner CW. The influence of impact object characteristics on impact force and force absorption of mouthguard material. Dent Traumatol 2004;20:12-20.

22. Guevara PH, Hondrum SO, Reichl RB. A comparison of commercially available mouthguards and a custom mouthguard. Gen Dent 2001; 49: 402-6.

23. Maeda M, Takeda T, Nakajima K, Shibusawa M, Kurokawa K, Shimada A, et al. In search of necessary mouthguard thickness. Part 1: From the viewpoint of shock absorption ability. Nihon Hotetsu Shika Gakkai Zasshi 2008;52(2):211-9.

24. Francis K, Brasher J. Physiological effects of wearing mouthguards. Br J Sports Med 1991;25(4):227-31.

25. Patrick D, van Noort R, Found M. Scale of protection and the various types of sports mouthguard. Br J Sports Med 2005;39(5):278-81.

26. Westerman B, Stringfellow P, Eccleston J. Beneficial effects of air inclusions on the performance of ethylene vinyl acetate (EVA) mouthguard material. Br J Sports Med 2002;36(1):51-3. 
27. Takeda T, Ishigami K, Handa J, Naitoh K, Kurokawa K, Shibusawa M, et al. Does hard insertion and space improve shock absorption ability of mouthguard?. Dental Traumatology. 2006;22(2):77-82.

28. Mendel D, Sanli Y, Brantley WA, Rashid RG, Harrell SL, Grentzer TH. Energy absorption of three mouthguard materials at higher impact speed. J Dent Res 2004;83 (Special Issue A):CD-ROM. [Abstract No. 565].

29. Mendel D, Sanli Y, Brantley WA, Rashid RG, Harrell SL, Grentzer TH. Energy absorption characteristics of three mouthguard materials. J Dent Res 2005;84 (Special Issue A):CD-ROM. [Abstract No. 420].

30. Coto N, Brito e Dias R, Costa R, Antoniazzi T, de Carvalho E. Mechanical behavior of ethylene vinyl acetate copolymer (EVA) used for fabrication of mouthguards and interocclusal splints. Braz Dent J 2007;18:324-8.

31. Mendel DA, Ucar Y, Brantley WA, Rashid RG, Harrell SL, Grentzer TH. Impact energy absorption of three mouthguard materials in an aqueous environment. Dent Traumatol 2009;25:130-5.

32. Westerman B, Stringfellow P, Eccleston J. The effect on energy absorption of hard inserts in laminated EVA mouthguards. Aust Dent J 2000;45(1):21-3.

33. Oikarinen K, Salonen M. Introduction to four custom-made mouth protectors constructed of single and double layers for activists in contact sports. Endod Dent Traumatol 1993;9(1):19-24.

34. Standard test method for high speed puncture properties of plastics using load and displacement sensors. ASTM Standard D 3763-98, June 1998. 